\title{
HVMANITAS
}

\section{Europa sob o olhar de Cabo-verde}

Autor(es): $\quad$ Pereira, Susana Marques

Publicado por: $\begin{aligned} & \text { Faculdade de Letras da Universidade de Coimbra, Instituto de Estudos } \\ & \text { Clássicos }\end{aligned}$

URL

persistente:

DOI: $\quad$ DOI:http://dx.doi.org/10.14195/2183-1718_63_35

Accessed : $\quad$ 26-Apr-2023 11:20:26

A navegação consulta e descarregamento dos títulos inseridos nas Bibliotecas Digitais UC Digitalis, UC Pombalina e UC Impactum, pressupõem a aceitação plena e sem reservas dos Termos e Condições de Uso destas Bibliotecas Digitais, disponíveis em https://digitalis.uc.pt/pt-pt/termos.

Conforme exposto nos referidos Termos e Condições de Uso, o descarregamento de títulos de acesso restrito requer uma licença válida de autorização devendo o utilizador aceder ao(s) documento(s) a partir de um endereço de IP da instituição detentora da supramencionada licença.

Ao utilizador é apenas permitido o descarregamento para uso pessoal, pelo que o emprego do(s) título(s) descarregado(s) para outro fim, designadamente comercial, carece de autorização do respetivo autor ou editor da obra.

Na medida em que todas as obras da UC Digitalis se encontram protegidas pelo Código do Direito de Autor e Direitos Conexos e demais legislação aplicável, toda a cópia, parcial ou total, deste documento, nos casos em que é legalmente admitida, deverá conter ou fazer-se acompanhar por este aviso. 
humanitas

Vol. LXIII

2011 


\title{
EUROPA SOB O OLHAR DE CABO-VERDE
}

\author{
Susana Marques Pereira \\ Universidade de Coimbra
}

\begin{abstract}
Resumo:
O multiculturalismo é uma prerrogativa de tempos ancestrais, que se reflecte também no mito. A recriação da lenda de Europa incluída no artigo 'A Europa e nós outros' do cabo-verdiano Germano Almeida evidencia particularidades identificativas de um povo específico, que nela projecta vivências próprias, e permite vislumbrar a relação estabelecida entre um 'eu' africano e um 'outro' europeu.

Palavras-chave: Europa, Cabo-verde, multiculturalismo, mito, Germano Almeida.

\section{Abstract}

Multiculturalism was no less prevalent in ancient than in modern times, as can be seen from ancient myths. The recreation of the Europa legend in the article 'Europe and us' by the Cape-verdian writer Germano Almeida highlights features that identify a specific people projecting into the said myth its own experience and establishing a linh between an 'African I' and a 'European other'.

Keywords: Europe, Cape Verde, multiculturalism, myth, German Almeida.

"Quantos caminhos e sendas já corridos E ainda em ovo o futuro por cumprir: Europa".

J. Ribeiro Ferreira, "O futuro sempre por cumprir"1
\end{abstract}

${ }^{1}$ (2002), A outra face do labirinto. Coimbra: 65. 
A confluência no espaço europeu de indivíduos com origens e culturas distintas é uma realidade já registada com ênfase por géneros diversos como a historiografia e a tragédia gregas do século $\mathrm{V}$ a. C., reflexo de uma época que evidenciou o contraste entre os Helenos e 'os outros', os que não falavam grego, os 'bárbaros’2 (cf. Heródoto, Histórias; Ésquilo, Persas, Eurípides, Hécuba, Orestes $\left.{ }^{3}\right)$.

Outras etapas da História da Humanidade, ainda na Antiguidade greco-romana, fizeram sobressair a aproximação e o encontro entre povos diversos, revelando-se como ocasiões propensas à miscigenação, biológica e cultural, em particular durante o governo de Alexandre Magno e no Período Helenístico (séculos IV-II/ I a. C.), ou com a Romanização (séculos III a. C. sqq.). Os Descobrimentos e a Colonização, na Época Moderna (séculos XV-XVIII), bem como a Descolonização e os múltiplos fluxos migratórios ainda em curso na Época Contemporânea marcam também momentos privilegiados de contacto multicultural entre os autóctones de uma Europa territorialmente bem mais ampla do que a definida no século V a. C. e 'o outro', agora entendido como o indivíduo/ grupo pertencente a grandes famílias culturais como a asiática, a americana, a africana.

A fusão de culturas, prerrogativa afinal de todos os tempos, é sobremodo notória na Europa hodierna, cenário permanente de uma paisagem humana multiétnica em constante actualização. Naturalmente, a relação estabelecida entre elementos oriundos de culturas diversas pode ir da mera partilha do espaço ("multiculturalismo de coexistência") à troca de experiências e saberes ("multiculturalismo de convivência")", num cruzamento

${ }^{2}$ Sobre o recurso à diferenciação linguística como primeiro critério definidor de uma identidade 'bárbara', i. e., não falante de grego, bem como sobre novas acepções que aquele termo acaba por encerrar, cf. Fialho, M. C. (2005): "Representações de identidade e alteridade em Ésquilo", Génese e consolidação da Ideia de Europa I: de Homero ao fim da época clássica. Coimbra: 77 sqq.

3 A propósito da diferença grego/ bárbaro em Heródoto, cf. Soares, C. (2001), "Tolerância e xenofobia ou a consciência de um universo multicultural nas Histórias de Heródoto", Humanitas 53: 49-82; sobre o tratamento do mesmo assunto pela tragédia, cf. Silva, M. F. S. (2005), "O bárbaro e o seu mundo no teatro de Eurípides", Ensaios sobre Eurípides. Lisboa: 15-91.

${ }^{4}$ A este propósito, cf. filmes como "A Turma" de L. Cantet (2008) ou "O dia da saia" de Jean-Paul Lilienfeld (2008), ilustrativos das dificuldades de diálogo em sociedades contemporâneas com uma paisagem cultural plural. As divergências entre os indivíduos/ grupos decorrem com frequência do receio do alter, do 
favorecedor ora da preservação de identidades fechadas, ora do diálogo capaz de promover a manutenção de identidades próprias.

No actual puzzle intercultural do velho continente, testemunho de uma Europa cada vez mais africana no que respeita à etnicidade, se integra o Cabo-verdiano, caracterizado por uma forte consciência da sua identidade étnica e cultural, enraizada a nível colectivo ${ }^{5}$. Impelido pelas circunstâncias da vida do seu arquipélago, bem como por uma natural curiosidade relativa à Europa, o nativo da antiga colónia portuguesa proporciona a interpenetração de culturas no território dos colonizadores de outrora, que se converte agora em palco privilegiado de mestiçagem.

Numa Europa que proclama com sensatez o incentivo à "cooperação com os países terceiros e às organizações internacionais competentes no domínio da cultura" (cf. artigo 128 do Tratado de Maastricht), transmitindo uma imagem de abertura a relacionamentos culturais com os não europeus, de diálogo com o outro, é absolutamente fundamental colher o retrato que esse alter apresenta do velho continente, a partir do seu mundo. Reflectir sobre essa representação pode evitar ou permitir compreender conflitos resultantes de desajustes entre expectativas de uns e atitudes e comportamentos de outros culturalmente diferentes, que se entrecruzam no quotidiano.

Em consonância com a variedade do património cultural herdado e aceite por cada indivíduo/grupo, também as perspectivas de abordagem de determinados temas podem ser divergentes, definidoras de especificidades e tradutoras de experiências de vida e/ ou épocas peculiares.

$\mathrm{O}$ mito, forma de cultura universal e intemporal, encerra um cerne imutável que torna uma história reconhecível em qualquer tempo e lugar, como se sabe ${ }^{6}$. No entanto, é motivo de renovadas leituras, de acordo com diferentes vivências que nele se projectam, o que traduz a sua vitalidade e potencial também no mundo contemporâneo. A actualização do mito por

desconhecido, da intolerância face ao que o 'outro' representa.

Sobre o multiculturalismo na Europa e as formas de relacionamento intercultural, cf. e. g. Lamo de Espinosa, E., ed. (1995), Culturas, estados, ciudadanos. Una aproximación al multiculturalismo en Europa. Madrid.

${ }^{5}$ Cf. Ferreira, M. (1985, $3^{\text {a }}$ ed.), A Aventura crioula. Lisboa: 8-9.

${ }^{6}$ Cf. Aristóteles, Poética 53b: “As histórias tradicionais, por exemplo, a morte de Clitemnestra às mãos de Orestes (...), não devem ser alteradas, mas o poeta deve, ele próprio, ser criativo, e usar bem os dados tradicionais". Trad. de Valente, A. M. (2004) in Aristóteles. Poética. Lisboa. 
uma comunidade determinada imprime-lhe traços da identidade própria desse grupo, instigando-o a sobrevalorizar intencionalmente certos elementos e situações em detrimento de outros, mesmo se mais convencionais.

O mito de Europa, reiteradamente tratado por múltiplos autores europeus, numa pluralidade de recriações e de domínios que vai da Literatura $^{7}$ à Numismática ${ }^{8}$, da Pintura ${ }^{9}$ à Música $^{10}$ ou à Cartografia ${ }^{11}$, mereceu a atenção do escritor contemporâneo Germano Almeida, que o incluiu num relato ilustrativo da visão que o 'outro' tem da Europa: "A Europa e nós outros" 12 . De origem cabo-verdiana, o autor evoca com frequência memórias da sua infância, vivida sob o regime colonial, dando a conhecer a realidade do seu povo com humor e com o sentido crítico de um indivíduo nascido em África, formado no espaço europeu - em Portugal -, e regressado à terra natal ${ }^{13}$. Através de diversas crónicas e romances, Germano Almeida, que congrega em si os papéis de advogado, editor, deputado, autor e jornalista, desvenda também o contexto actual do universo crioulo em que reside, a nível sócio-político e cultural, estabelecendo com frequência um paralelo entre o Cabo-verde colonial e o pós-independência. Se nas suas linhas podemos entrever alusões a topoi convencionais cabo-verdianos,

${ }^{7}$ Nomes como Estesícoro (fr. 195 PMG), Mosco de Siracusa (Idílio II) ou Ovídio (Met. 2. 837 sqq.) ilustram diferentes abordagens, na Antiguidade Clássica, de um mito de grande projecção também na Literatura moderna (cf. e. g. Roberto Calasso, As núpcias de Cadmo e Harmonia, David Mourão-Ferreira, "Retrato de rapariga"; Nuno Júdice, "O rapto de Europa", José Ribeiro Ferreira, "O futuro sempre por cumprir"). Sobre fontes da Antiguidade para o tema do rapto de Europa, cf. Sánchez-Marín, J. A. (2009), "Europa”, En Grecia y Roma, III: mujeres reales y fictícias. Pociña Pérez, A., García González, J. M., eds. Granada: 515-535.

${ }^{8}$ Cf. e. g. actuais moedas gregas de dois euros.

${ }^{9}$ Cf. e. g. Veronese (séc. XVI), "O rapto de Europa", Simon Vouet (séc. XVII), "O rapto de Europa", Gustave Moreau (séc. XIX), "Jupiter et Europe”, Henri Matisse (séc. XX), "O rapto de Europa".

${ }^{10}$ Cf. e. g. Darius Milhaud (sécs. XIX-XX), L'enlèvement d'Europe.

${ }^{11}$ A este propósito, cf. Pinho, S. T. (2003), "A descrição camoniana da Europa e a cartografia ginecomórfica”, Separata da Revista Camoniana -3 $3^{\text {a }}$ s.-vol. 14. Bauru-S. Paulo: 185-228.

12 Oceanos 16 (1993): 40-42.

${ }^{13}$ Germano Almeida reuniu cinquenta e cinco crónicas distintas desta no volume Estórias Contadas - sobremodo associadas ao quotidiano vivido no seu país natal, reflectem um estilo próprio, que não se coíbe de desvendar com graça a realidade do povo cabo-verdiano. 
como a insularidade ou a emigração, descobrimos em simultâneo uma imagem do quotidiano do arquipélago relativa por exemplo a questões sociais, a anseios, a gostos que singularizam o indivíduo/ o povo de Cabo-verde.

Em vários dos seus textos, Germano Almeida insiste na relação entre os Cabo-verdianos e 'os outros', sejam estes Europeus ou Africanos, para distinguir os seus conterrâneos, a sua identidade peculiar e distintiva. É neste contexto de relação entre um 'eu' de Cabo-verde e um 'outro', desta feita Europeu, que surge a menção ao mito de Europa, reformulado, e como um motivo não sistemático nas suas crónicas ${ }^{14}$.

A história do amor de Zeus por Europa, a bela princesa fenícia que o deus, metamorfoseado em touro, conduziu ao Ocidente, onde consumou a sua paixão e viu nascer descendência, é por demais conhecida, tendo sido amplamente desenvolvida na Antiguidade quer pelo poeta helenístico Mosco de Siracusa (Idílio II), quer, em língua latina, por Ovídio, nas Metamorfoses (2. 837 sqq.), a par de menções mais breves de outros autores ${ }^{15}$. De facto, Mosco de Siracusa imaginou um sonho enviado por Cípris a Europa, premonitório do rapto da jovem, a anteceder uma ida da donzela ao prado com as companheiras para apanhar flores, motivo convencionalmente associado ao tema do rapto de uma figura feminina ${ }^{16}$; concebeu também o disfarce de Zeus sob a figura de um touro, o arrebatamento da apaixonada, a viagem pelo mar até Creta, onde Europa gerou filhos do deus, que acabou por lhe revelar a sua verdadeira identidade. Ovídio, por seu turno, sem aludir ao sonho, concentrou-se nas ordens de Júpiter a Mercúrio para preparar o rapto da apaixonada no litoral de Sídon, bem como na descrição da beleza magnífica do touro, no desejo divino de união com 'a filha do grande rei' e no arrebatamento da donzela através das águas marinhas. $\mathrm{O}$ autor registou ainda a busca empreendida em vão por Cadmo, irmão da princesa, para a encontrar e o estabelecimento do mesmo em Tebas (Met. 3. 3), numa alusão a fundações fenícias que outrora se foram espalhando pelo mundo ocidental. Pelo recurso à lenda, o homem europeu procurou as

${ }^{14}$ A par desta alusão a um tema clássico, surgem noutras composições referências a Deus, numa mescla que evidencia a fusão entre paganismo e universo cristão.

${ }^{15}$ Cf. Sánchez-Marín 2009: 517 sqq.

${ }^{16}$ Sobre o motivo do rapto de uma personagem feminina, cf. Sánchez-Marín 2009: 515; Silva, M. F. S. (2005): "Elementos visuais e pictóricos em Eurípides", Ensaios sobre Eurípides. Lisboa: 330 sqq. 
suas raízes identitárias, estabelecendo uma ligação civilizacional entre o Ocidente e o Oriente, patrocinada pelos deuses ${ }^{17}$.

Que Europa é porém aquela sobre a qual Germano Almeida medita? Quem são 'os outros' a quem o autor se refere?

Com Cabo-verde por cenário de uma história recriada pelo universo crioulo, o escritor reflecte a ideia de um autóctone desse país sobre uma Europa outrora idealizada, porquanto ainda desconhecida - 'da Europa só conhecíamos os belos nomes: quintas, coutadas, jardins, palácios, reis, barões...' Como na Antiguidade clássica, a percepção do 'outro', geograficamente distante, exercia um fascínio inegável sobre o ego, estimulador do seu imaginário: ' ...quer nas estórias quer na vida, a Europa sempre significou um mito romântico'.

Todavia, como nota oportunamente A. M. Tarrío ${ }^{18}$, a propósito do património cultural europeu hodierno, 'a Europa iludida, raptada pelas artimanhas de Júpiter, tornou-se ela própria através dos séculos Europa eludens, agente de desilusão e decepção'. No relato de Germano Almeida, ao conhecimento mítico da Europa, seguiu-se, algures em África, o geográfico, o político, o económico... De modo sintomático, o autor afirma: 'por mim, no entanto, preferi ficar para sempre com a imagem da menina raptada na praia por um deus manhento e astuto', num testemunho ilustrativo de que o contacto com a realidade implicou o desfazer do sonho que a lenda criara, a falta de correspondência entre o objecto de desejo e a utopia.

A visão mítica do velho continente, aquela que se pretende destacar nestas páginas, constituiu um primeiro olhar lançado à Europa por todos aqueles que escutavam com prazer as estórias memoráveis de "nho Quirino', na ilha cabo-verdiana da Boavista. Entre esses ouvintes incluíase o próprio Germano Almeida, que confere um registo escrito à lenda, gravando para a posteridade todos os elementos etnográficos, sociais, his-

${ }^{17}$ George Steiner, em A Ideia de Europa, acentua precisamente a herança oriental do velho continente, no quarto axioma com que o define, na actualidade.

Heródoto, Hist. 1. 1-2 racionaliza o mito, interpretando-o como a expressão da origem das rivalidades entre Gregos e bárbaros: o rapto de Europa pelos Helenos seria uma resposta a igual feito perpetrado pelos Fenícios em relação a Io, à qual teriam levado para o Egipto.

18 (2003), "Elusa Europa. Do património cultural europeu”, Antiguidade Clássica: que fazer com este património? - Colóquio à memória de Victor Jabouille. Lisboa: 297-305. 
tóricos, culturais nela implícitos. A narrativa oral de 'nho Quirino', na senda da mais antiga forma de comunicação entre os homens e dos próprios costumes do Arquipélago, permanece como uma porta de acesso a um mito que congrega tradição e inovação, para realçar renovadas vivências e intencionalidades: pelas palavras simples de um 'eu' que integra uma comunidade específica, fisicamente participante da lenda, se vai transmitindo e preservando um saber natural, mesclado de elementos da Antiguidade grecolatina e africanos. Como salienta M. Ferreira ${ }^{19}$, o povo Cabo-verdiano "não se resigna a copiar padrões de cultura, antes de tudo recria através da sua própria individualidade, de tal modo que não sendo impossível (...) destrinçar <nas histórias tradicionais> os elementos de raiz afro-negra e os que subsistiram de origem europeia, todos no entanto iluminam, mercê de solicitações colectivas íntimas e específicas, um cunho de originalidade ganho por vagarosa e segura reelaboração'. Na verdade, se a narrativa de 'nho Quirino' inclui aspectos da versão clássica, que se conservam (as figuras, a paixão de Zeus por Europa, a transformação do deus num animal, o rapto da jovem no litoral e a travessia dos mares), omite porém alguns e acrescenta outros, de tonalidade marcadamente autóctone, que reflectem experiências de uma colectividade com referências culturais distintas (e. g., a comparação de Europa com outras 'moças' da ilha da Boavista, o gosto desta figura feminina por 'expor a sua nudez nas praias da sua ilha, ingenuamente indiferente aos estragos que ia provocando nos corações de cada um').

No espaço do imaginário cabo-verdiano, Europa assume a identidade de uma jovem africana, merecedora de admiração pela sua aparência incrível, que a superioriza em relação às demais 'moças' da Boavista. A singularidade desta personagem feminina, símbolo de um 'outro' cativante, centra-se na beleza física apetecível, como na tradição clássica, e dota-a ainda de magia e encantamento, capazes de 'transformar as feras mais selvagens em cabritos alegres e dóceis'. Europa não é agora a princesa oriental que viajou para Ocidente e gerou descendência, mas, em vez disso, assume uma configuração local - cabo-verdiana da ilha da Boavista - e manifesta-se sobretudo na sua beleza revelada ao 'outro', provocadora, adequadamente enquadrada num cenário natural que sublinha a tonalidade específica da realidade geográfica em que o mito é reformulado.

19 1985: 87. 
Ao relato poético ilustrativo da necessidade que o homem europeu sente de explicar as raízes da sua identidade, esta lenda sobrepõe a expressão de uma mentalidade colectiva que destaca essencialmente o fascínio e o enamoramento de outrora dos Cabo-verdianos por uma Europa ainda por desvendar. Nesse sentido, dá-se sobremodo relevo à identidade e caracterização da jovem e à paixão que Zeus nutre por ela. Como os demais deuses de outrora, Zeus era semelhante aos homens, nomeadamente no 'especial fraco pelas mulheres bonitas', proximidade que estreita a conexão entre o indivíduo/ grupo e a história narrada.

Com as atenções focadas no desejo divino por Europa, o mito descreve um tópico em particular, numa linguagem que remete para um cenário determinado: o dia em que, 'lá do alto do céu, Zeus a viu assim nuinha tomando banho de sol na areia branca de uma praia', numa alusão ao fabuloso litoral da ilha e à sedução provocada por um corpo jovem, feminino, estendido na areia. Nesta versão, Europa não se encontra acompanhada por outras jovens, nem a colher flores, mas antes sozinha e numa postura mais aliciadora do desejo de a desvelar: a sua nudez espraiada à beira-mar era profundamente tentadora, como aliás a própria narrativa denuncia ('a sua nudez (...) ia provocando <estragos> nos corações de cada um'). A Zeus, nem Hera, 'mulher terrível que lhe castigava as infidelidades a chicote de cavalo-marinho e que uma vez tinha mesmo ameaçado capá-lo', o impediu de concretizar a enorme vontade de se unir a Europa, 'transformado num esplêndido e manso boi' que acabou por seduzi-la e, 'atravessando os mares', por ocultá-la 'numa ilha perdida'. Nas estórias de 'nho Quirino', não se identifica essa ilha com Creta, enfatizando a relação específica com o berço civilizacional da Europa, a Grécia, como se sabe, mas alude-se, de modo indefinido, a um local eventualmente situado no velho continente: a recriação do mito incide com especial atenção no aspecto relacional entre culturas distintas.

A versão contada na Boavista não se refere tão pouco à descendência de Zeus e de Europa: sublinha-se que a mestiçagem entre Africanos e Europeus é amorosa, mesmo se na vida real não é só assim - esse amor, quando concretizado em procriação, traduz o cruzamento biológico efectivo entre povos, implicando que a identidade entre uns e outros se esboce com base na troca, na reciprocidade.

A menção de Germano Almeida à lenda termina com a convicção de que, nessa ilha, Zeus 'ainda no tempo das estórias de 'nho Quirino' e para sempre, continuava a amá-la', símbolo de laços eternos, de um amor sólido entre Cabo-verde e uma Europa intensamente sonhada, apetecida, desejada 
- o homem crioulo imprime ao mito um cunho próprio, modelando-o à sua mentalidade, à sua cultura, à sua história.

Pela recriação da lenda percebe-se que Europa pode apresentar faces distintas, delineadas pelo espaço, pela época e pelas gentes que compõem a sua história a partir da visão que têm do mundo e da humanidade, a partir dos seus próprios comportamentos: a jovem ora pertence a raças e nacionalidades diversas, ora a diferentes sistemas linguísticos, sociais, políticos e religiosos. Susceptível de se identificar com várias pertenças em simultâneo, esta Europa oriunda das entranhas de um 'eu' culturalmente diferenciado vê estabelecer-se um elo intemporal entre culturas. A sua história, seja enquanto princesa oriental, seja sob a aparência de uma jovem caboverdiana, acaba por revelar-se sobremodo como uma forma de questionar as relações entre 'uns' e os 'outros', temática de cariz universalista, que ultrapassa as fronteiras territoriais do arquipélago crioulo.

Permita-se que a visão apaixonada da Europa se sobreponha a uma percepção decepcionante da verdadeira realidade com que o não europeu muitas vezes se vê surpreendentemente confrontado...

Permita-se que seja cumprido o sonho cabo-verdiano de outrora sobre uma Europa fantástica, ainda a descobrir....

'E que tem a Europa a ver com o touro e com o mito?

O tudo e o nada,

Que o mito é a voz do sonho a ser futuro' ${ }^{20}$.

\section{Bibliografia $^{21}$}

Aristóteles. Poética (2004). Trad. de Valente, A. M.. Lisboa.

Ferreira, J. R. (2002), A outra face do labirinto. Coimbra.

FERreira, M. (1985), A aventura crioula. Lisboa.

FerreIRA, M. (06.03.1990), "Cabo-Verde, a terceira via estética”, Jornal de Letras, Artes e Ideias: Lisboa: 27.

Fialho, M. C. (2005), "Representações de identidade e alteridade em Ésquilo", Génese e consolidação da Ideia de Europa I: de Homero a fim da época clássica. Coimbra: 77-93.

${ }^{20}$ Ferreira, J. R. (2002), "O futuro sempre por cumprir", A outra face do labirinto. Coimbra: 65.

${ }^{21}$ Inclui apenas os títulos indicados no presente artigo. 
Lamo de Espinosa, E., ed. (1995), Culturas, estados, ciudadanos. Una aproximación al multiculturalismo en Europa. Madrid.

LeITE, A. M. (26.11.1991), “Algo de novo na ficção cabo-verdiana”, Jornal de Letras, Artes e Ideias. Lisboa: 14.

Pinho, S. T. (2003), "A descrição camoniana da Europa e a cartografia ginecomórfica", Separata da Revista Camoniana - $3^{\text {a }}$ s., vol. 14. Bauru-S. Paulo: 185-228.

Sánchez-Marín, J. A. (2009), "Europa”, En Grecia y Roma, III: mujeres reales y fictícias. Pociña Pérez, A., García González, J. M., eds. Granada: 515-535.

Silva, M. F. S. (2005), Ensaios sobre Eurípides. Lisboa.

SoARES, C. (2001), "Tolerância e xenofobia ou a consciência de um universo multicultural nas Histórias de Heródoto", Humanitas 53: 49-82.

Steiner, G. (2006, $3^{\text {a }}$ ed.), A Ideia de Europa. Trad. de St. Aubin, M. F. Lisboa.

TArrío, A. M. (2003), “Elusa Europa. Do património cultural europeu”, Antiguidade Clássica: que fazer com este património? - Colóquio à memória de Victor Jabouille. Lisboa: 297-305.

Tolpa, H., in Biblos: Enciclopédia Verbo das Literaturas de Língua Portuguesa 1, s. v. Almeida, Germano da Cruz: 155-156. 